\title{
A interdisciplinaridade na legislação educacional, no discurso acadêmico e na prática escolar do Ensino Médio: panaceia ou falácia educacional?+*
}

\author{
Erika Regina Mozena ${ }^{1}$ \\ Fernanda Ostermann ${ }^{2}$ \\ Instituto de Física - Universidade Federal do Rio Grande do Sul \\ Porto Alegre - RS
}

\section{Resumo}

O discurso da interdisciplinaridade no Brasil tem sido apropriado por grande parte da legislação educacional desde a década de 70 com o sentido de responsabilizá-la por elevar a educação a patamares superiores de qualidade. Na mesma direção, crescem vertiginosamente os trabalhos de pesquisa na área de educação, que apontam a importância da interdisciplinaridade no contexto atual. Por outro lado, tanto esses documentos legais como os meios acadêmicos outorgam ao professor o papel de desenvolver e implementar a interdisciplinaridade na sala de aula. O que se observa em trabalhos de pesquisa que investigam a prática dos professores é que estes se contentam em empreender projetos que julgam interdisciplinares, mas que em sua grande maioria não passam de multidisciplinares, apoiados no senso comum. Este quadro coloca o discurso da interdisciplinaridade com feições de uma falácia educacional. Este trabalho discute a insistência histórica da legislação e do meio acadêmico em tornar este discurso um grande objeto do desejo educacional. Já com relação aos professores, procura localizar as razões pelas quais eles não se aprofundam nessa prática além do senso comum, análise apoiada na epistemologia da prática docente como pensada por Tardif e Lessard, que justifica as ações dos professores com base nas características intrínsecas das situações do trabalho interativo.

\footnotetext{
${ }^{+}$Interdisciplinary in educational legislation, in academic discourse and in High School practice: panacea or educational fallacy?

* Recebido: junho de 2015. Aceito: fevereiro de 2016.

${ }^{1}$ E-mail: erikamozena@hotmail.com

2E-mail: fernanda.ostermann@ufrgs.br
} 
Palavras-chave: Interdisciplinaridade; Legislação educacional; Prática Docente.

\begin{abstract}
The discourse about interdisciplinarity in Brazil has been widely incorporated in the educational legislation since the 70s, and it has been considered as a tool to bring education to higher quality levels. In the same direction, currently there is a significant growth in researches pointing to the importance of interdisciplinarity. On the other hand, both oficial documents and the academia consider the teacher as the responsible to develop and implement interdisciplinary in the classroom. What is observed in studies that investigate the practice of teachers is that teachers undertake projects they conceive as interdisciplinary, but most of them are only multidisciplinary, supported by the common sense. This framework puts the interdisciplinarity discourse as an educational fallacy. This paper discusses the historical insistence of legislation and academia to elevate this discourse as a large object of the educational desire. In relation to the teachers, this work searches the reasons why they do not deepen this practice, with a theoretical analysis supported by the epistemology of practice teaching as thought by Tardif and Lessard, which justify teachers' actions based on intrinsic characteristics of the situations of interactive work.
\end{abstract}

Keywords: Interdisciplinarity; Educational legislation; Teaching practice.

\title{
I. Introdução
}

A interdisciplinaridade tem sido considerada um paradigma em emergência no cenário mundial desde a década de 60 . Ultimamente este tema tem ganhado bastante destaque no meio acadêmico e constatamos um aumento significativo de publicações na área de ensino de ciências, com reconhecida relevância para a Educação (MOZENA; OSTERMANN, 2014a).

Esse tema também tem sido destacado nas recentes políticas públicas para a educação, que culminaram com a aprovação do Plano Nacional de Educação ou PNE (2014-2024), que visa entre outros aspectos a "(...) incentivar práticas pedagógicas com abordagens interdisciplinares (...)” (BRASIL, LEI No 13.005/2014, Meta 3, estratégia 3.1). Imbricado com o PNE, podemos visualizar outras ações governamentais ligadas à interdisciplinaridade, como: a proposta de um redesenho curricular anunciado pelo MEC desde 2012, com integração das disciplinas no ensino médio (MOZENA; OSTERMANN, 2014b), o ENEM estabelecido de maneira 
integrada por áreas, a valorização de propostas interdisciplinares no PNLEM, a tramitação da lei n. 6840/2013 e a expansão do Programa Ensino Médio Inovador (ProEMI), que financiou até o 2014 o redesenho curricular na sala de aula, com vistas à integração das disciplinas.

Essa gradativa institucionalização da interdisciplinaridade no cenário educacional brasileiro atribui uma conotação bastante positiva para este conceito, praticamente como se este fosse panaceia para os problemas educacionais brasileiros. Mas afinal, o que é essa tal de interdisciplinaridade? Qual a sua relação com integração curricular? O que dizem a legislação educacional brasileira e os especialistas em educação sobre ela? E os professores, como se apropriam da interdisciplinaridade em suas salas de ensino médio? Procuraremos, ao longo deste texto, responder a estas questões e mostrar que o assunto exige aprofundamento teórico e muito critério, para que esta noção não seja abandonada num futuro próximo sem a justa compreensão e possa um dia ser considerada uma falácia educacional sem ao menos ter sido implementada adequadamente.

\section{A interdisciplinaridade escolar segundo o discurso acadêmico}

Segundo a socióloga Fernanda Antônia da Fonseca Sobral ${ }^{3}$, a partir do século XX, com o advento da Física Moderna, o paradigma hegemônico da ciência clássica passa a ser questionado a partir de três pilares: ordem, separabilidade e a lógica formal.

Nesse panorama, surge o paradigma interdisciplinar, que tem como base a ideia de que o conhecimento é complexo e, portanto, não pode ser apreendido em sua essência por meio de suas partes. No entanto, essa mesma complexidade permite apenas vislumbrar uma de suas perspectivas por vez (o clássico dilema filosófico parte-todo atribuído a Descartes ${ }^{4}$ ). A interdisciplinaridade, nesse sentido, seria uma mudança de atitude frente ao conhecimento, uma leitura mais abrangente de troca, de reciprocidade, entre essas perspectivas na busca por "uma substituição da concepção fragmentária para a unitária do ser humano" (TAVARES, 2011, p. 29).

A interdisciplinaridade constitui-se, assim, numa atitude não apenas pautada numa intenção holística, mas também, segundo Frigotto (2008):

(...) uma necessidade imperativa pela simples razão de que a parte que isolamos ou arrancamos "do contexto originário do real" para poder ser explicada efetivamente, (...) tem que ser explicitada na integridade das características e qualidades da totalidade (FRIGOTTO, 2008, p. 48).

\footnotetext{
${ }^{3}$ Em palestra proferida no ILEA (UFRGS). Disponível em: <http://www.adufrgs.org.br/noticias/universidade-dofuturointerdisciplinaridade-na-pesquisa-e-fundamental-diante-da-complexidade-da-ciencia/>. Acesso em: dez. 2014.

${ }^{4}$ Augusto (2014, p. 7).
} 
Em termos de ensino, a interdisciplinaridade escolar é considerada um paradigma oriundo da falência da organização curricular por disciplinas tradicionais na escola (FAZENDA, 2011), que promove um acúmulo de informações, mas pouco contribui para a vida ativa e profissional das pessoas.

Apesar dessas bases bem estabelecidas, o conceito de interdisciplinaridade é bastante polissêmico. Ivani Fazenda, pesquisadora renomada do tema no Brasil na área de Educação e também a autora mais citada como referencial teórico de pesquisa em nossa revisão bibliográfica sobre interdisciplinaridade (MOZENA; OSTERMANN, 2014a), promove amplo debate sobre a conceituação de interdisciplinaridade, mas não tece uma definição única do termo, no que é seguida por outros autores, justificando que este conceito não possui um sentido único e estável.

(...) esta característica polissêmica tem muito a contribuir para bases sólidas de reflexão crítica, justamente por não aquietarem nossas concepções. Portanto, penso que o movimento de acomodação do termo resultaria em morte de sentido (MIRANDA, 2013, p. 124).

Também Fazenda e o GEPI (Grupo de Estudos e Pesquisa em InterdisciplinaridadePucSP) não se preocupam com distinções entre multidisciplinaridade (ou pluridisciplinaridade) e interdisciplinaridade, apenas situando a primeira como "(...) uma atitude de justaposição de conteúdos de disciplinas heterogêneas” e na segunda “(...) uma relação de reciprocidade, da mutualidade, ou melhor dizendo, um regime de copropriedade que iria possibilitar o diálogo entre os interessados" (FAZENDA, 1992, p. 39). Para Fazenda, a transdisciplinaridade (considerada utópica) evocaria o nível mais alto dessas relações.

Segundo Santomé (1998), Jean Piaget engendra as seguintes definições:

1. Multidisciplinaridade. O nível inferior de integração. Ocorre quando, para solucionar um problema, busca-se informação e ajuda em várias disciplinas, sem que tal interação contribua para modificá-las ou enriquecê-las. Esta costuma ser a primeira fase da constituição de equipes de trabalho interdisciplinar, porém não implica que necessariamente seja preciso passar a níveis de maior cooperação.

2. Interdisciplinaridade. Segundo nível de associação entre disciplinas, em que a cooperação entre várias disciplinas provoca intercâmbios e, consequentemente, enriquecimentos mútuos.

3. Transdisciplinaridade. É a etapa superior de integração. Trata-se da construção de um sistema total, sem fronteiras sólidas entre as disciplinas, ou seja, de "uma teoria geral de sistemas ou de estruturas, que inclua estruturas operacionais, estruturas de regulamentação e sistemas probabilísticos, e que una estas diversas possibilidades por meio de transformações reguladas e definidas (SANTOMÉ, 1998, p. 70). 
Apesar da falta de uma definição precisa, numa revisão de literatura da área de ensino de ciências/Física, percebemos (MOZENA; OSTERMANN, 2014a) que certas posições mostram-se como consenso entre a grande maioria das pesquisas analisadas. Esses artigos, pautados teoricamente em trabalhos como os de Ivani Fazenda, Edgar Morin, Jurjo Santomé, Gerard Fourez, Yves Lenoir e Hilton Japiassu, sinalizam a necessidade de superação de um ensino fragmentado, linear e descontextualizado. Em sua grande maioria, situam a interdisciplinaridade, no contexto escolar do ensino médio, como um diálogo, uma relação ou uma negociação entre um ou mais conhecimentos disciplinares escolares, não necessariamente apenas os tradicionais (ou seja, não apenas física, química, história, geografia, mas também a ética, a cidadania, a jurisdição, a medicina, a engenharia etc.). Há também grande preocupação, nos trabalhos analisados, com os conteúdos específicos das disciplinas e na metodologia de ensino utilizada para materialização da interdisciplinaridade.

Nesse sentido, o papel da interdisciplinaridade no contexto educacional é muito importante na atualidade e o professor tem um papel fundamental na sua implementação: ela pode ser efetivada por um único professor em sua sala de aula, ou pode ser desenvolvida numa metodologia pautada em projetos, embora isso possa significar ações bem diferentes. Assim, a interdisciplinaridade é comumente usada na escola para: esclarecer uma situação, resolver um problema ou compreender algo em seu contexto o mais próximo possível do real ou cotidiano. E pode ser ainda desenvolvida em aula por meio de projetos variados, histórias explanatórias, aprendizagem baseada em resolução de problemas, desenvolvimentos de modelos, atividades multivariadas, textos diversificados, recursos hipermídia, aulas-diálogo etc., além de avaliada por meio de mapas conceituais (MOZENA; OSTERMANN, 2014a).

Em teoria, a interdisciplinaridade não constitui a negação ou extinção das disciplinas, nem um cruzamento (ou superposição) de disciplinas, a multidisciplinaridade. Também não se opõe às disciplinas, “(...) ao contrário, não pode existir sem ela e, mais ainda, alimenta-se dela” (LENOIR, 1998, p.46). Parafraseando a socióloga Fernanda Antônia da Fonseca Sobral, "a disciplina tem que estar forte para conseguir dar o braço à outra". Ainda é preciso levar em consideração que "conseguimos dar o braço mais facilmente ao parente", ou seja, a interdisciplinaridade é mais facilmente materializada entre áreas afins, como é o caso das disciplinas das ciências da natureza.

Outro aspecto importante diz respeito ao fato de que a interdisciplinaridade escolar é diversa da interdisciplinaridade na pesquisa, o que impede a simples transposição de saberes entre ambas, como observado por Lenoir (1998):

[...] a interdisciplinaridade escolar trata das "matérias escolares", não de disciplinas científicas. Mesmo se as matérias escolares tomam certos empréstimos às disciplinas científicas, não constituem cópias de maneira alguma, tampouco resultam de uma simples transposição de saberes eruditos [...] (p. 48). 
[...] considerando-se a existência de grandes diferenças entre as disciplinas científicas e as disciplinas escolares, as suas finalidades são diferentes, seus objetivos são diferentes, e também o são as modalidades de aplicação e suas referências (p. 51).

Elucidando melhor essa questão, Lopes (2002,) assinala que:

[...] as disciplinas escolares são diferentes das disciplinas de referência, na medida em que cumprem finalidades sociais diversas e na medida em que os conhecimentos escolares são constituídos especificamente para fins de ensino por processos de recontextualzação (Bernstein, 1998) e de transposição didática (Chevallard, s.d.). (p. 148).

Uma metáfora bastante simplificadora para a interdisciplinaridade é apresentada por Ferreira (2011):

[...] o conhecimento é uma sinfonia. Para a sua execução será necessária a presença de muitos elementos: os instrumentos, as partituras, os músicos, o maestro, o ambiente, a plateia, os aparelhos eletrônicos etc. A orquestra está estabelecida. Todos os elementos são fundamentais descaracterizando, com isso, a hierarquia de importância entre os membros. Durante os ensaios as partes se ligam, se sobrepõem e se justapõem num movimento contínuo, buscando um equilíbrio entre as paixões e os desejos daqueles que as compõem. O projeto é único: a execução da música. Apesar disso, cada um na orquestra tem sua característica, que é distinta. Cada instrumento possui elementos que o distinguem dos demais. $O$ violino é diferente do piano, tanto na forma como na maneira de ser tocado. Para que a sinfonia aconteça, será preciso a participação de todos. A integração é importante, mas não fundamental. Isto por que na execução de uma sinfonia é preciso harmonia do maestro e a expectativa daqueles que assistem (FERREIRA, 2011, p. 33-34).

Já a conceituação de interdisciplinaridade, pautada num viés fenomenológico por Fazenda e seu grupo de estudos (GEPI), é bastante polissêmica, refletida, embasada teoricamente e abrangente. Embora se preocupem mais com a pesquisa, nossa análise sobre os enunciados de Fazenda e o GEPI, efetuados em tese de doutorado (MOZENA, 2014), mostra que a interdisciplinaridade é encarada, mesmo com relação à escola, como uma atitude, uma maneira de lidar com o conhecimento, que extrapola os conteúdos e prioriza o ser humano. Essa abordagem é fundamentada por alguns princípios de vida: totalidade/complexidade, intenção, humildade, espera, respeito, coerência, desapego, diálogo, ordem e rigor, partilha, coragem, solidão etc.

Atitude de quê?? Atitude de busca de alternativas para conhecer mais e melhor; atitude de espera frente aos atos não consumados; atitude de reciprocidade que impele à troca, que impele ao diálogo, com pares idênticos, com pares anônimos ou consigo mesmo; atitude de humildade frente à limitação do próprio ser; atitude de perplexidade frente à possibilidade de desvendar novos saberes; atitude de desafio, desafio frente ao novo, desafio em redimensionar o velho; atitude de envolvimento e compro- 
metimento com os projetos e com as pessoas neles envolvidas; atitude, pois, de compromisso em construir sempre da melhor forma possivel; atitude de responsabilidade, mas, sobretudo, de alegria, de revelação, de encontro, enfim, de vida (FAZENDA, 2010, p. 170).

Sendo assim, Fazenda e o GEPI priorizam uma compreensão de interdisciplinaridade que valoriza o lado humano das relações entre as disciplinas, e o perfil do professor como pesquisador, que deve "perceber-se interdisciplinar" (FAZENDA, 2011, p.77). Suas posições valorativas impregnam-se tanto pela concepção de interdisciplinaridade defendida, que esta fundamenta todas as suas ações no trabalho de estudo e investigação. Segundo esses autores, a interdisciplinaridade precisa ser vivida.

Um destaque dessa ação interdisciplinar tem relação com a parceria. Fazenda e seu grupo estudam, debatem e até mesmo escrevem juntos. Uma colaboração bastante positiva, engendrada com bastante rigor e respeito ao outro que, aliás, apresenta uma funcionalidade invejável, atestada por sua extensa produção na área e o reconhecimento internacional do seu trabalho.

Apesar da valorização deste seu tema de pesquisa, Fazenda aponta que "Interdisciplinaridade não é uma panaceia que garantirá um ensino adequado, ou um saber unificado, mas um ponto de vista que permite uma reflexão aprofundada, crítica e salutar sobre o funcionamento do mesmo" (FAZENDA, 1992, p. 41). Segundo essa autora, o valor e a aplicabilidade da interdisciplinaridade podem ser pensados como: meio de conseguir uma melhor formação geral, meio de atingir uma formação profissional, incentivo à formação de pesquisadores e pesquisas, condição para uma educação permanente, superação da dicotomia ensino-pesquisa, forma de compreender e modificar o mundo, além de considerar a integração como necessidade à interdisciplinaridade (FAZENDA, 1992).

Apesar de serem usados muitas vezes como sinônimo, um ensino interdisciplinar não significa necessariamente integração curricular. Segundo Santomé (1998), Richard Pring “considera a primeira denominação mais apropriada para referir-se à inter-relação de diferentes campos do conhecimento com finalidades de pesquisa ou de solução de problemas" (p.112), enquanto que a integração curricular seria mais adequada "(...) para ressaltar a unidade que deve existir entre as diferentes disciplinas e formas de conhecimento" (idem), de maneira que a disciplina deixa de ser hegemônica para subordinar-se a uma forma de integração.

Para Lopes (2002, p. 149), o conceito de integração curricular se relaciona às formas de compreensão das disciplinas escolares, que no pensamento clássico podem ser organizadas em currículo: por competências, centrado nas disciplinas de referência ou nas disciplinas escolares. Segundo essa autora a organização curricular acaba se transformando no grande mote de mudança no ensino, de maneira que os PCNEM (1998), centrados nas competências, buscavam expressar um padrão de mudança com o discurso da interdisciplinaridade, mas promoveram estabilidade ao currículo do ensino médio ao manterem as disciplinas tradicionais. De alguma 
forma, essa organização está sendo atualmente reestruturada com a nova configuração curricular pautada em áreas.

No entanto, tanto Fazenda como o GEPI também colocam a interdisciplinaridade na responsabilidade do professor (que deve ser melhor formado) e, nos parece que pela natureza de pesquisa de seus textos, não dialogam diretamente com o ele, não aproximando suas reflexões da prática docente.

\section{A interdisciplinaridade escolar no discurso oficial: histórico e legislação educacional para o ensino médio}

O movimento pela interdisciplinaridade surgiu na Europa na década de 60, principalmente na França e Itália, “[...] época em que surgem os movimentos estudantis, reivindicando um novo estatuto de universidade e escola" (FAZENDA, 2011, p. 18), já que ambas, da maneira como se apresentavam, não serviam para a vida.

[...] a Europa anunciou, na década de 1960, a interdisciplinaridade como uma forma de oposição ao saber alienado, como um símbolo de retorno do humano ao mundo [...] sua meta não é a de originar uma nova ciência que se situaria para além das disciplinas particulares, mas seria uma "prática" específica visando à abordagem de problemas relativos à existência cotidiana (TRINDADE, 2013, p. 84).

O próprio termo interdisciplinaridade é originalmente atribuído a Piaget e teve como principal alavancador Georges Gusdorf, que em 1961 apresentou à Unesco um projeto de pesquisa interdisciplinar. Fazenda (2011) assinala que sua principal conclusão do colóquio de 1967, em Louvain, foi a de que: "um dos caminhos indicados para o estudo da dicotomia ser/existir seria a discussão interdisciplinar sujeito humano/mundo" (Idem, p. 21).

A interdisciplinaridade chegou ao Brasil ao final desta década de 60 e, segundo Fazenda, “[...] com sérias distorções, próprias daqueles que se aventuraram ao novo sem reflexão, ao modismo sem medir as consequências do mesmo" (FAZENDA, 2011, p. 23).

Apesar da palavra interdisciplinaridade não estar especificada na Lei de Diretrizes e Base (LDB) de 1971 (Lei 5692/71), nota-se relação com o conceito no artigo 21, que explicita a ideologia da época pautada em "integrar para desenvolver": "O ensino de $2^{\circ}$ grau destina-se à formação integral do adolescente"5.

De acordo com Fazenda (1985), essa ideologia transparece de maneira contundente no relatório dos grupos de trabalho organizados pelo então ministro Jarbas Passarinho que culminaram com a promulgação desta LDB, de maneira a constituir-se numa "ideologia da integração, pressupondo-se professores e alunos como super-homens, capazes de assumir sozinhos toda a problemática educacional" (FAZENDA, 1985, p. 87).

\footnotetext{
5 Lei no 5.692, de 11 de agosto de 1971. Disponível em: <http://presrepublica.jusbrasil.com.br/legislacao/128525/lei-de-diretrizes-e-base-de-1971-lei-5692-71>. Acesso em: abr. 2015.
} 
Nos relatórios desses grupos de trabalho não houve um consenso conceitual para o tema e existiam "[...] para a propugnada integração, pressuposto da estrutura de lei, diferentes conotações, o que dificulta a compreensão do que e como integrar" (FAZENDA, 1985, p. 87). Também houve, nesses documentos, segundo Fazenda, "utilização indevida de termos - além de não existir na lei uma indicação clara e precisa das implicações teóricas de um trabalho interdisciplinar" (idem). Fazenda ainda assinala que:

[...] tal como aparece no texto do Relatório, foi um bom artifício utilizado para confundir especialistas em educação e não-especialistas. Na tentativa de decifrar esse enigma [...] os educadores perdiam seu tempo e desviavam sua atenção dos problemas mais reais da educação, calando-se... (FAZENDA, 1985, p. 87).

Nesse caso, "Produziu-se uma ideologia para a burguesia neotecnocrática dominante e essa produção ficou a cargo da parte liberal da classe burguesa” (FAZENDA, 1985, p. 115).

Assim, apesar da LDB de 1971 ser bastante sucinta, omitindo as discussões envolvidas nos grupos de trabalho, para Fazenda (1985) "o símbolo integração foi circunscrito de tal forma à "salvação da educação nacional" que passou a ser "real representante dessa Educação salvadora, e quem pode questionar uma educação que salva?” (FAZENDA, 1985, p. 92).

Era o "milagre educacional" que se difundia fortemente na transição da década de 60 para 70, através do mito de que a educação seria salva através da aplicação de métodos de ensino importados, já que a preocupação com a política educacional era vetada, dado o período sombrio de ditadura militar.

No âmbito legal, o termo interdisciplinaridade foi introduzido apenas em 1972 (FAZENDA, 2007, p. 34), época em que integração designava na legislação uma hierarquia de conteúdos cuja principal preocupação era a multidisciplinaridade, e a interdisciplinaridade era meramente um trabalho em equipe para se obter a integração (Idem). Fazenda é enfática em dizer que "A forma como tratam do problema vem reforçar a conclusão de que não se sabe ainda o que, como e o que efetivamente representa interdisciplinaridade em termos de legislação" (Idem, p. 35).

Entre os especialistas em educação da década de 70, procurava-se "[...] uma definição para a interdisciplinaridade" (FAZENDA, 2011, p. 18), sendo que a grande preocupação era de explicitação terminológica, já que "[...] interdisciplinaridade era uma palavra difícil de ser pronunciada e, mais ainda, de ser decifrada" (Idem).

Nessa época, as discussões eram derivadas daquelas oriundas sobre o papel humanista do conhecimento e da ciência e tinham como tônica a questão da totalidade (FAZENDA, 2011, p. 19). O primeiro pesquisador brasileiro a discutir sobre a interdisciplinaridade no Brasil foi Hilton Japiassu, em 1976, com o livro "Interdisciplinaridade e Patologia do Saber", muito embora sua grande pauta seja relativa às questões da pesquisa interdisciplinar, que é de outra natureza da escolar. 
Em 1979 é lançada a primeira obra de Fazenda, fruto do seu mestrado. Em sua tese de doutorado, realizou um estudo sobre a implementação de reformas educacionais na década de 70 , pautadas na interdisciplinaridade, em que observou a maneira superficial com que o tema interdisciplinaridade foi tratado. Isso provocou, aliado a certa alienação e ao regime governamental da época (militar), o desinteresse dos educadores da época pelo assunto.

[...] procedi a uma ampla visita à Legislação do Ensino, constatando o descaso, a falta de critério, de informações e perspectivas que subsidiam a implementação de um projeto reformista da educação na década de 70. A análise apontou para um caos generalizado, a partir do caos conceitual que se instalou.

A alienação e o descompasso no trato das questões mais iniciais e primordiais da interdisciplinaridade provocaram não apenas o desinteresse, por parte dos educadores da época, em compreender a grandiosidade de uma proposta interdisciplinar, como contribuiu para o empobrecimento do conhecimento escolar. O barateamento das questões do conhecimento no projeto educacional brasileiro da década de 1970 conduziu a um esfacelamento da escola e das disciplinas. À pobreza teórica e conceitual agregaram-se outras tantas que somadas condenaram a educação a 20 anos de estagnação (FAZENDA, 2011, p. 26).

Segundo Fazenda, as ações políticas educacionais eram permeadas por conveniências, que paulatinamente silenciaram a voz dos educadores. Tudo isso frente à mudez da imprensa $\mathrm{e}$ à manutenção de interesses escusos:

Uma visita às decisões dos poderes Legislativo e Executivo esclareceu-me sobre o quadro de "conveniências", no qual a educação para a interdisciplinaridade foi gestada. Analisei como foram gradativamente caladas as vozes dos educadores, dos alunos, e o processo de entorpecimento pelo qual passaram as consciências esclarecidas, analisei também a mudez da imprensa e o conluio desonesto na articulação das propostas educacionais.

[...] Foi tempo de silêncio, iniciado no final dos anos 50, que percorreu toda a década de 1960 e a de 1970. Somente a partir de 1980 as vozes dos educadores voltaram a ser pronunciadas. A interdisciplinaridade encontrou na ideologia manipuladora do Estado seu promotor maior. Entorpecido pelo perfume desse modismo estrangeiro, o educador se omitiu e nessa omissão perdeu aspectos da sua identidade pessoal (FAZENDA, 2011, p. 30).

Com o final da ditadura na década de 80, o Brasil iniciou seu processo de estruturação para fundamentação da democracia e a educação nacional também participou deste movimento, tendo suas bases legais bastantes modificadas. Nesta década, segundo Fazenda: "tentávamos explicitar um método para a interdisciplinaridade" (FAZENDA, 2011, p. 18). Essa época caracterizou-se mais pela busca dos princípios teóricos das práticas vivenciadas por alguns professores. Apesar disso, "[...] a interdisciplinaridade continuou a se disseminar de forma indiscriminada, já que, de fato, poucos professores a conheciam” (TRINDADE, 2013, p. 85). 
Na Constituição promulgada em 5 de outubro de 1988, ficou definida como competência da União legislar sobre as diretrizes e bases da educação nacional, abrindo com isto a possibilidade de reformulação da legislação educacional brasileira. O processo de tramitação da nova Lei de Diretrizes e Bases da Educação iniciou-se na Câmara Federal em dezembro de 1988 e foi aprovada em 1996 pelo presidente Fernando Henrique Cardoso.

Entre outras resoluções da nova LDB, cuja finalidade passa a ser "o pleno desenvolvimento do educando, seu preparo e exercício da cidadania e sua qualificação para o trabalho" (BRASIL, LDB, 1996, art. $2^{\circ}$ ), o antigo segundo grau, que antes era visto apenas como um meio de acesso à Universidade passou a ter função formativa para a cidadania. Essa lei institucionalizou, assim, o ensino médio, sua universalização de acesso, os exames nacionais de desempenho, a necessidade de superação da repetência, a valorização do magistério, a democratização da gestão educacional, o programa de avaliação do livro didático e a elaboração das diretrizes nacionais para o ensino básico.

Como contingência da LDB, as Diretrizes Curriculares Nacionais para o Ensino Médio (DCNEM) foram instituídas em 1998, sendo fundamentadas pelo desenvolvimento de competências e habilidades nos educandos, além do "tratamento metodológico que evidencie a interdisciplinaridade e a contextualização" (BRASIL, Resolução CEB n ${ }^{\circ} 3 / 98$, art. 10, §1 ${ }^{\circ}$ ).

Estas diretrizes serviram, então, de base para as propostas curriculares nacionais efetuadas pelo Governo Federal: os Parâmetros Curriculares Nacionais (PCN) em 2000, os Parâmetros Curriculares Nacionais Complementares (PCN+), em 2002, e as Orientações Curriculares para o Ensino Médio (2006). Também foram elaboradas muitas propostas estaduais. Todas essas propostas são de caráter facultativo, não tendo, portanto força de lei ou norma.

No esteio à crítica ao ensino por competências, à evolução do debate de concepções humanistas e sociais, à emergência de grupos sociais distintos reivindicando seu espaço e à mudança de orientação partidária do Governo Federal, novas Diretrizes Curriculares Gerais da Educação Básica (DCGEB) foram aprovadas em 2010, sendo seguidas pelas novas Diretrizes Curriculares Nacionais do Ensino Médio (DCNEM), promulgadas em janeiro de 2012.

Nestes documentos, desapareceram do cenário nacional os termos "competências" e "habilidades" e a "interdisciplinaridade" reaparece com seu viés metodológico de maneira realmente institucionalizada, pois agora devem ser reservados $20 \%$ da carga horária anual a projetos interdisciplinares na escola (BRASIL, Resolução CEB no 4/2010, Art. 17). Também são tomados como fundamentos do novo Ensino Médio o trabalho e a pesquisa, respectivamente, como princípios educativo e pedagógico. O Quadro 1 fornece um panorama dos entornos legislativos e curriculares com relação ao ensino médio desde a LDB.

Com relação à legislação, analisamos em Mozena (2014), a Lei de Diretrizes e Bases da Educação (LDB) que nem ao menos cita a palavra interdisciplinaridade, as DCNEM (1998) que a invocam principalmente como tratamento metodológico, as DCGEB (2010) que destacam parte da carga horária para a interdisciplinaridade e as DCNEM (2012) que a estabelecem como base de organização. Essa consolidação da interdisciplinaridade historicamente aconteceu ao 
longo dos anos, aliada a trocas partidárias do Governo Federal e a um interesse cada vez mais evidente pela promoção de um ensino médio integrado por áreas.

Quadro 1: Legislação e propostas curriculares para o ensino médio desde a LDB.

\begin{tabular}{|c|c|c|}
\hline Políticas Públicas & Implicações para o Currículo do Ensino Médio & Caráter \\
\hline LDB (1996) & $\begin{array}{l}\text { Estabelece a elaboração de propostas curriculares na- } \\
\text { cionais e regionais, além de autonomia para Escola e } \\
\text { Professor. }\end{array}$ & \multirow{2}{*}{$\begin{array}{l}\text { Obriga- } \\
\text { tório }\end{array}$} \\
\hline DCNEM (1998) & $\begin{array}{l}\text { Constituição no aluno de competências e habilidades, } \\
\text { pautados na interdisciplinaridade e contextualização. }\end{array}$ & \\
\hline \begin{tabular}{l}
\multicolumn{3}{l}{ Propostas Curriculares } \\
Nacionais: PCN \\
$(2000)$, PCN+(2002) e \\
Orientações Curric. \\
para o Ens. Médio \\
$(2006)$
\end{tabular} & $\begin{array}{l}\text { Ciências da Natureza: as disciplinas Biologia, Quí- } \\
\text { mica e Física não se conversam interdisciplinarmente. } \\
\text { Apresentam blocos de conteúdos e procedimentos. }\end{array}$ & \multirow[t]{2}{*}{$\begin{array}{l}\text { Faculta- } \\
\text { tivo }\end{array}$} \\
\hline $\begin{array}{l}\text { Propostas Curriculares } \\
\text { Estaduais }\end{array}$ & $\begin{array}{l}\text { Regionalização: Minas Gerais, São Paulo, Paraná, Rio } \\
\text { Grande do Sul (2009), Santa Catarina, Goiás etc. }\end{array}$ & \\
\hline DCNGEB (2010) & $\begin{array}{l}\text { Projetos interdisciplinares: } 20 \% \text { carga horária anual. } \\
\text { Gestão democrática de organização da escola. }\end{array}$ & \multirow{2}{*}{$\begin{array}{l}\text { Obriga- } \\
\text { tório }\end{array}$} \\
\hline DCNEM (2012) & $\begin{array}{l}\text { Trabalho como princípio educativo. } \\
\text { Pesquisa como princípio pedagógico. } \\
\text { Interdisciplinaridade como base de organização. }\end{array}$ & \\
\hline
\end{tabular}

Nossa compreensão ativa da interdisciplinaridade nesses documentos, empreendida por análise pautada principalmente em Bakhtin (1995 e 1977) e Veneu (2012) e apresentada em Mozena (2014), é de que esta concepção não é apresentada de maneira clara, pois estes textos não fornecem informações precisas e adequadas do que é interdisciplinaridade e de como efetivá-la na sala de aula, nem reflexões ou justificativas adequadas ao seu público. A interdisciplinaridade mostra-se como um conceito confuso, mostrando que os elaboradores desses documentos não se aprofundaram no tema. O que encontramos foram textos sem embasamento teórico, com interpretações inadequadas, contradições, sem referências, ou referências ausentes, o que mostra que, em alguns casos, não houve nem mesmo uma revisão cuidadosa neste material, ocorrências que não podem existir em documentos tão importantes e de escala nacional. Nesses documentos, a interdisciplinaridade também é, principalmente, apresentada em relação aos conteúdos das disciplinas. 
Todos esses aspectos nos levam a pontuar alguns motivos pelos quais a interdisciplinaridade reina soberana nesses documentos. Em primeiro lugar está o contexto histórico descrito da evolução da legislação e do debate acadêmico sobre o tema desde a década de 70 no Brasil, apoiada desde aquela época em modismos estrangeiros, que de certa forma instituiu a interdisciplinaridade como uma ideologia salvadora. Conclusão esta nada diferente daquela apresentada no final da década de 80 por Fazenda (2011, p. 24).

Também acreditamos que a institucionalização da interdisciplinaridade no âmbito escolar do ensino médio tenha relação restrita com a intenção desvelada por parte do Governo Federal em promover um ensino integrado por áreas no ensino médio (MOZENA; OSTERMANN, 2014b). Comparando os resultados de Fazenda com nossas análises baseadas em documentos legais mais recentes, não vemos muitas diferenças no quadro geral, apesar da situação política, econômica e social serem bem diversas. Vemos políticas educacionais serem gestadas e desenvolvidas com pretextos aparentemente nobres, mas que, em grande parte, escondem interesses governamentais ou do setor privado. Como exemplo, podemos citar o redesenho curricular no ensino médio, proposto em 2012 pelo então ministro Aloizio Mercadante, com a intenção de integrar as disciplinas e aparentemente melhorar a formação integral do aluno, quando, numa leitura mais crítica, provavelmente, escondem questões relativas à falta de professores especialistas, como os de Física. A imprensa até hoje dá pouca atenção ao assunto e não revela que essa integração já é uma realidade em muitas escolas brasileiras, através do financiamento do Programa Ensino Médio Inovador. Nesse caso, a integração fica a cargo do professor, que como nossas pesquisas mostram, não está preparado para uma ação interdisciplinar e acaba não avançando além do senso comum.

Tanto na legislação que pesquisamos, quanto nos resultados de Fazenda e seu grupo, a participação docente na realização de reformas educativas e na identificação dos problemas pertinentes à classe ainda não existe:

As novas políticas públicas não fizeram mais do que atualizar uma velha tendência nacional - a formulação de políticas e planos de capacitação docente sem a participação dos professores, portanto desconhecedora da real situação desses profissionais $[\ldots]$.

O professor com o qual contam as reformas educativas contemporâneas, no discurso e no papel, ainda não foi inventado, ainda não existe (LIMA, 2013, p. 198).

Nessa perspectiva, Fazenda (2011) também nos alerta que a interdisciplinaridade não pode simplesmente romper com as práticas educacionais consolidadas historicamente, mesmo com relação aos conteúdos e que há a necessidade sim de desenvolver a competência disciplinar e interdisciplinar:

Um processo de intervenção, seja na escola de $1^{o}$ e $2^{o}$ grau ou superior, que não saiba partir do que já existe, que procure romper com o passado de práticas já consolida- 
das, que desorganize o que está organizado, que desconsidere os conteúdos tradicionalmente trabalhados tende rapidamente à falência, pois rompe com o movimento natural da história (p. 78-79).

Na pesquisa que realizamos na legislação brasileira (MOZENA, 2014), também percebemos que não houve diálogo com o professor sobre a interdisciplinaridade: textos abstratos, formais, demasiadamente concisos, confusos e praticamente sem exemplos, não fazem sentido ao professor. Todos os documentos analisados foram unânimes em outorgar ao professor o encargo de exercê-la, dentro da autonomia que lhe é assegurada e das condições sócio históricas e culturais da comunidade em que a escola e os alunos se inserem. Mas como os professores são responsáveis por algo que não fez parte da sua educação enquanto alunos, nem da sua formação profissional? Como outorgar-lhes tamanha responsabilidade se não lhes é oferecido qualquer arcabouço teórico ou exemplos de como efetivá-la na sala de aula? Parece-nos óbvio que ao transferir ao professor uma incumbência para a qual ele não está preparado, o único desfecho possível é um desastre educacional, que com certeza implicará um repúdio à ideologia interdisciplinar.

\section{A interdisciplinaridade na prática escolar do ensino médio: a multidisciplinaridade}

E os professores do ensino médio? Como eles estão lidando com essa tarefa e efetivando a interdisciplinaridade na sala de aula? Estamos mesmo caminhando para um desastre? As pesquisas têm indicado (e.g. ALVES, 2013; AUGUSTO et al., 2004; GERHARD; ROCHA FILHO, 2012) que, na sala de aula, as práticas interdisciplinares dos professores acabam se materializando na multidisciplinaridade, que segundo Fourez (2003) é:

\section{[...] a prática de reunir os resultados de diversas disciplinas científicas em torno de um tema comum, sem visar um projeto específico. Muitos currículos ou programas de ensino se limitam a ser multidisciplinares, quer dizer, a reunir um conjunto do ensino de diversas disciplinas sem articulação entre elas (FOUREZ, 2003).}

Ou seja, multidisciplinaridade é o costume em se reunir com os outros professores, definir um tema e, na sequência, cada professor abordar solitariamente em sua sala de aula aquele tema focado na sua disciplina, sem a explicitação das relações com as outras matérias escolares.

Apontamos essa ocorrência durante a formação continuada dos professores do ensino médio nas Lições do Rio Grande ${ }^{6}$, da qual participamos (MOZENA, 2014; MOZENA; OSTERMANN, 2013; MOZENA; OSTERMANN; CAVALCANTI, 2011). Nesse caso, o grande tema escolhido foi a Copa do Mundo da África e os trabalhos perdiam completamente o seu foco interdisciplinar quando o professor de geografia estudava com os alunos em sua sala de aula sobre a África, por exemplo, o de história sobre apartheid, de biologia sobre a origem do

\footnotetext{
${ }^{6}$ O referencial curricular do Estado do Rio Grande do Sul, publicado em 2009.
} 
homem na África, o de física sobre a física do futebol, de química sobre doping etc. Na multidisciplinaridade, apenas o tema em comum caracteriza um trabalho que continua sendo essencialmente disciplinar na sala de aula.

Vários dos trabalhos analisados em nossa revisão bibliográfica (MOZENA; OSTERMANN, 2014a), também indicam algo elementar, mas que parece esquecido pelos elaboradores de propostas curriculares: os professores apresentam dificuldades para trabalhar interdisciplinarmente simplesmente por que não tiveram esse tipo de educação enquanto alunos, ou não foram preparados adequadamente em sua formação inicial para tal intento.

Segundo Tardif (2012) e Tardif e Lessard (2012), a profissão docente é essencialmente uma profissão de interações humanas, um trabalho interativo e situado, e como tal sujeito a condicionantes, demandas e problemas de relações humanas. Sob esse referencial, ao reconhecermos os professores como competentes, sujeitos ativos, devemos admitir que a prática deles não seja somente um espaço de aplicação de saberes provenientes da teoria, mas também um espaço de produção de saberes específicos oriundos dessa mesma prática.

Assim, procuramos em Mozena (2014), pautados em Tardif e Lessard, descrever e analisar algumas atividades materiais e simbólicas de alguns professores circunscritas em 103 projetos interdisciplinares produzidos em formação continuada, procurando compreender quais são e como esses professores lidam com os saberes curriculares a respeito da interdisciplinaridade, como assumem e recontextualizam as orientações curriculares, em função de suas necessidades profissionais e de seu contexto cotidiano de trabalho com os alunos. Como nossa disciplina de base é a física, os projetos analisados foram elaborados por professores de várias disciplinas do ensino médio, com a necessária participação de pelo menos um professor de física em cada um deles.

$\mathrm{Na}$ referida pesquisa, percebemos, na esteira de muitas outras pesquisas da revisão de literatura, que a interdisciplinaridade não passa para esses professores de multidisciplinaridade, que eles realizam com certa boa vontade, pois julgam que é positiva e importante.

Apesar dessa premência, percebemos que a interdisciplinaridade é ainda considerada como uma prática não legítima por grande parte dos professores, pois a consideram como algo a mais, mas que lhes rouba um tempo precioso em que deveriam trabalhar conteúdos do livro didático que "caem no vestibular". O professor do ensino médio, em função da carga exaustiva de trabalho, não tem tempo para a interdisciplinaridade.

Ainda a maneira como o professor efetiva a interdisciplinaridade é aquela adequada para ele, sendo que nem parece imaginar que seu trabalho poderia ser melhor nessa área. Outro viés importante no trabalho interdisciplinar em equipe na escola parece ser a oportunidade do professor mostrar aos seus pares e dirigentes que pode fazer um trabalho com os alunos diferente e divertido, embora essa ação deva ser pontual.

Assim, analisando os condicionantes e demandas dos professores, pautados em Tardif e Lessard, vemos que a interdisciplinaridade está injustamente outorgada a ele, que vive um dia a dia extremamente atribulado, exercendo um papel de "malabarista profissional", lidando com 
dilemas de difícil resolução, pois atua em um ambiente complexo, impossível de controlar, assumindo funções diversas e contraditórias.

Agregada a estes resultados, temos a socialização dos docentes enquanto alunos e o seu agir através do tempo, que propiciam que eles façam de suas próprias atividades recursos para reproduzir essas mesmas atividades: os professores interiorizam regras implícitas de ação adquiridas com e na experiência.

Também as rotinas adquiridas e herdadas pela tradição desencadeiam atitudes reprodutivas, o que justifica o fato de que, ao realizarem seus projetos multidisciplinares, os professores ganharam o reconhecimento dos alunos que se divertiram com as aulas diferentes, e, mais ainda, o reconhecimento dos pares ao divulgarem seus trabalhos nos seminários do curso das Lições do Rio Grande, nos quais foram ovacionados. Nesse processo, provavelmente os professores interiorizaram que esta prática multidisciplinar foi um sucesso e, provavelmente, permanecerão replicando-a ao longo de sua carreira.

Em essência, devido às características intrínsecas das situações de trabalho interativo, os professores transformaram e adaptaram a interdisciplinaridade promulgada pela legislação e pelos meios acadêmicos em função das exigências do seu dia a dia, o que resultou em um trabalho multidisciplinar, apoiado no senso comum (MOZENA, 2014). Sua autonomia e sua responsabilidade se situam assim bem no centro dessa tarefa codificada e programada conforme situações concretas do cotidiano, sendo que os principais ajustamentos são feitos, sobretudo, devido a limitações de tempo.

Notamos também que a disciplina de Física se mostrou como um ponto nevrálgico para a interdisciplinaridade quando empreendida em larga escala na escola, ficando de lado em muitos projetos ou colocada no projeto de maneira forçada ou não relacionada. A principal justificativa é a de que quando se pensa em um projeto que envolva muitos professores, o lado humano acaba se sobressaindo, de maneira que a física acaba "sem voz".

Provavelmente falte também aos professores de Física uma formação mais sólida em sua disciplina e o entendimento de relações que o ensino de física pode estabelecer com as ciências humanas que lhes permita com mais facilidade aprofundar os assuntos que não dominem e também perceber as relações com as outras disciplinas.

\section{Discussões}

A interdisciplinaridade está tanto teoricamente quanto legalmente instituída em nossas escolas. Sua valoração é bastante positiva, ainda que, como observamos na área de ensino de Física, tem sido abordada na pesquisa como elemento pontual, mas ainda se acredita em seu potencial como um fator para a melhoria da qualidade da educação brasileira.

Julgamos que a interdisciplinaridade, como proposta por Ivani Fazenda, realmente apresenta uma predisposição para se despertar a paixão, não só pelo conhecimento, mas pela atitude interdisciplinar. Acreditamos que a interdisciplinaridade nos permite conhecer melhor 
a nossa própria disciplina, promovendo uma atitude investigativa e dialógica de aprofundamento na companhia dos próprios alunos. E, nessa perspectiva, um dos grandes papéis da profissão docente está na mediação necessária para promover nos alunos a capacidade de estabelecer diálogos maduros e éticos com o conhecimento e com outros seres humanos, algo tão complicado no mundo atual.

No entanto, apresentamos como resultado que não há qualquer comunicação entre a legislação, especialistas em educação e o professor. E o que é pior, tanto a legislação como os especialistas em educação atribuem ao professor o papel de desenvolver e implementar a interdisciplinaridade na sala de aula, papel que na prática tem se fundamentado na multidisciplinaridade, em razão da formação, condicionantes e demandas dos professores.

Assim, não adianta continuar a criticar o professor e dizer que ele precisa estudar e mudar. Precisamos pensar em como, a partir do perfil do professor que temos, podemos, em parceria com ele, desenvolver um trabalho interdisciplinar mais amplo, mais apoiado na teoria e que transcenda a multidisciplinaridade.

Nessa direção, cremos que o papel do professor continua essencial na interdisciplinaridade escolar, mas esta não deve ser totalmente outorgada a ele. Uma parceria universidadeescola, sem verticalizações, com a participação de acadêmicos das áreas específicas e da educação pode ser um caminho frutífero para se efetivar a interdisciplinaridade escolar, explorando-se os limites de cada disciplina, como relacioná-la com as outras e quais os conteúdos adequados ao trabalho interdisciplinar.

Sem essa parceria, provavelmente, o professor continuará replicando a multidisciplinaridade que tem "dado certo" para ele na escola. E das duas uma: ou a interdisciplinaridade será abandonada dos bancos escolares, ou prosseguiremos formando novos professores que agora estão nos bancos escolares aprendendo que essa multidisciplinaridade funciona na sala de aula, promovendo assim a interiorização de regras implícitas de ação.

A interdisciplinaridade na sala de aula, principalmente nas disciplinas de ciências físicas e naturais, precisa ser melhor estudada e o professor mais respaldado nesse processo. Só assim se promoverá algum sucesso com essa metodologia de ensino e se evitará que ela seja descartada e rechaçada simplesmente por deficiente utilização.

Infelizmente, não há soluções mágicas. A interdisciplinaridade não é de maneira alguma panaceia para nos encontrarmos de vez com a tão idealizada e já famigerada "pátria educadora". No entanto, ela se mostra como um bom instrumento de reflexão e ação escolar, quando bem fundamentada. E talvez seja descartada justamente por sua incompreensão ou má utilização.

\section{Referências Bibliográficas}

ALVES, A. Interdisciplinaridade e matemática. In: FAZENDA, I.C. A. (Org.). O que é interdisciplinaridade? São Paulo: Cortez, 2013. p. 103-117. 
AUGUSTO et al. Interdisciplinaridade: concepções de professores da área ciências da natureza em formação em serviço. Ciência \& Educação, v. 10, n. 2, p. 277-289, 2004.

BAKHTIN, M. (V. N. Volochinov). Marxismo e filosofia da linguagem. São Paulo: HUCITEC, 1995.

BAKHTIN, M. M. Estética da criação verbal. São Paulo: Martins Fontes, 1977.

BRASIL. Ministério da Educação. Secretaria De Educação Básica. Programa Ensino Médio Inovador: documento orientador. 2014. Disponível em: <http://pactoensinomedio.mec.gov.br/images/pdf/doc_orientador_proemi_2014.pdf >. Acesso em: out. 2014.

. LEI No 13.005, de 25 de junho de 2014. Aprova o Plano Nacional de Educação PNE e dá outras providências. D.O.U. de 26/06/2014, p. 1. Edição extra. Brasília, DF.

. Resolução CEB no 4, de 13 de julho de 2010. Define Diretrizes Curriculares Nacionais Gerais para a Educação Básica. D.O.U. de 14/7/2010, Seção 1, p. 824. Brasil, Brasília, DF.

FAZENDA, I. C. (Org.) Interdisciplinaridade: história, teoria e pesquisa. 18. ed. Campinas: Papirus, 2011.

. (Org.) Metodologia da pesquisa educacional. São Paulo: Cortez, 2010. 2007.

Interdisciplinaridade: um projeto em parceria. 6. ed. São Paulo: Edições Loyola,

Integração e interdisciplinaridade no ensino brasileiro: efetividade ou ideologia. São Paulo: Edições Loyola, 1992.

Educação no Brasil anos 60: o pacto do silêncio. São Paulo: Edições Loyola, 1985.

FERREIRA, S. L. Introduzindo a noção de interdisciplinaridade. In: FAZENDA, I. C. A. (Org.) Práticas interdisciplinares na escola. São Paulo: Cortez, 2011. p. 33-35.

FRIGOTTO, G. A interdisciplinaridade como necessidade e como problema nas ciências sociais. Revista do Centro de Educação e Letras da Unioeste - Campus de Foz do Iguaçu, v. 10, n. 1, p. 42-62, 2008.

GERHARD, A. C.; ROCHA FILHO, J. B. da A fragmentação dos saberes na educação científica escolar na percepção de professores de uma escola de ensino médio. Investigações em Ensino de Ciências, v. 17, n. 1, p. 125-145, 2012.

LAVAQUI, V.; BATISTA, I. de L. Interdisciplinaridade em ensino de Ciências e de matemática no ensino médio. Ciência \& Educação, v. 13, n. 3, p. 399-420, 2007.

LENOIR, Y. Didática e interdisciplinaridade: uma complementaridade necessária e incontornável. In: FAZENDA, I. C. A. (Org.) Didática e interdisciplinaridade. Campinas: Papirus, 1998. p. $45-75$. 
LOPES, A. C. Parâmetros curriculares para o ensino médio: quando a integração perde seu potencial crítico. In: LOPES, A. C.; MACEDO, E. (Orgs). Disciplinas e integração curricular: história e políticas. Rio de Janeiro: DP\&A, 2002, p. 145-176.

MIRANDA, R. G. Da interdisciplinaridade. In: FAZENDA, I. C. A. (Org.). O que é interdisciplinaridade? São Paulo: Cortez, 2013. p. 119-130.

MOZENA, E. R. Investigando enunciados sobre a interdisciplinaridade no contexto das mudanças curriculares para o ensino médio no Brasil e no Rio Grande do Sul. 2014. $281 f$. Tese (Doutorado em Ensino de Física) - Instituto de Física, UFRGS, Porto Alegre.

.; OSTERMANN, F. Uma revisão bibliográfica sobre a interdisciplinaridade no ensino das ciências da natureza. Revista Ensaio, v. 16, 2014a.

Integração curricular por áreas com extinção das disciplinas no Ensino Médio: Uma preocupante realidade não respaldada pela pesquisa em ensino de física. Revista Brasileira de Ensino de Física, São Paulo, v. 36, n. 1, 1403, 2014b.

Investigando saberes experienciais dos professores de ciências sobre interdisciplinaridade no ensino público secundário no Rio Grande do Sul. In: CONGRESSO INTERNACIONAL SOBRE INVESTIGACIÓN EM DIDÁCTICA DE LAS CIENCIAS, IX, 2013. Girona. Anais eletrônicos... Girona: Enseñanza de lasCiencias, 2013, p. 2436-2440. Disponível em: <http://congres.manners.es/congres_ciencia/gestio/creacioCD/cd/articulos/art_292.pdf>. Acesso em: 13 jun. 2014.

CAVALCANTI, C. Lições do Rio Grande: um relato sobre o processo de elaboração dos referenciais curriculares para o ensino de Física no Rio Grande do Sul e o acompanhamento de cursos de formação continuada para professores nessa perspectiva. In: SIMPÓSIO NACIONAL DE ENSINO DE FÍSICA, XIX, 2011. Manaus. Anais... Manaus: SBF, 2011.

TAVARES, D. E. Aspectos da história deste livro. In: FAZENDA, I. C. A. (org.). Práticas interdisciplinares na escola. São Paulo: Cortez, 2011. p. 27-31.

SANTOMÉ, J. T. Globalização e interdisciplinaridade: o currículo integrado. Porto Alegre: Artes Médicas, 1998.

TARDIF, M. Saberes docentes e formação profissional. Petrópolis: Vozes, 2012.

.; LESSARD, C. O trabalho docente: elementos para uma teoria da docência como profissão de interações humanas. Petrópolis: Vozes, 2012.

VENEU, A. A. Perspectivas de professores de física do ensino médio sobre as relações entre o ensino de física e o mercado de trabalho: uma análise bakhtiniana. 2012. Dissertação (Mestrado em Educação em Ciências e Saúde) - Núcleo de Tecnologia Educacional para a Saúde, Universidade Federal do Rio de Janeiro, Rio de Janeiro. 